\title{
A Dialogue with the Present: Barriers and Breakthroughs in Traditional Literary Research
}

\author{
Xuelian Sheng ${ }^{1,2, *}$ \\ ${ }^{1}$ Northwest Minzu University, Lanzhou, Gansu 730000, China \\ ${ }^{2}$ Hexi University, Zhangye, Gansu 734000, China \\ *Corresponding author. Email: 13993668833@163.com
}

\begin{abstract}
As a branch of the study of Chinese literature, the study of the literature and folk literature in the mother tongue of different nationalities does not involve the "diversified literature". The network media, a new medium for literature, coupled with the evolution of literature transmission and inheritance, requires the transformation of the paradigm of literature research. Therefore, cultural research in the multicultural context is supposed to change the traditional literature research pattern of "elite culture" which takes "Han culture" as the mainstream, as well as to expand the space and time of minority cultural research. Such practice is of great significance to the construction of the territory of Chinese literature, the enrichment of the excellent traditional cultural system of the Chinese nation, the promotion of the development of literary theory and the construction of the critical discourse system.
\end{abstract}

Keywords: Multi-ethnic literature, Diversity, Broadening one's horizon.

\section{INTRODUCTION}

Throughout the evolution of history and literature, the concept of "Chinese nation" is often replaced by such concepts as "Han nationality" and "Han culture". The concept of pluralistic integration of the Chinese nation proposed by Fei Xiaotong at the end of the 20th century exerted huge impact on the history and literature circles. The splendid Chinese civilization, which has endured many vicissitudes, is extensive and profound, thanks to the joint efforts of the 56 ethnic groups who share weal and woe. According to the concept of pluralistic integration of the Chinese nation, the Han nationality is the core force that plays a cohesive role in the pluralistic structure. However, it only serves as one member of the "diverse structure". "Various nationalities" are the indispensable "members" in this whole.

\section{THE BARRIERS OF TRADITIONAL LITERATURE RESEARCH AND THE TRANSFORMATION OF RESEARCH PARADIGM}

General Secretary Xi Jinping's statement that "the 56 ethnic groups should be closely embraced like pomegranate seeds" conveys the spirit of "unity, equality and fraternity". The view of literary history with such connotation should stick to the integrity of Chinese nation's historical development and the independence of each nation's historical development, and break through the barriers of traditional literature research, changing the tendency of weakening "the literary characteristics of different nationalities" in previous literature studies. The multiplicity of Chinese literature as a whole should be treated objectively and justly, including the diversity of each ethnic culture, the blending of each ethnic culture and the cohesion of the Han culture. In this way, the vision of cultural studies can be expanded in the dimension of time and space, changing the distinction between Chinese literature and minority literature in literary history.

\subsection{More Attention Is Paid to "Elite Literature", While More Attention Is Paid to Writers' Literature in the Study of Ethnic Minority Literature, but Less to Ethnic Folk Literature}

In the past literature research, among the rich and colorful literary achievements involving the creation 
of various ethnic groups, "Han literature" used to take the lead in the literary world for a long time. Although the literary works of authors of other ethnic minorities received much attention, scholars preferred specific discourse time, culture and political moral standards. However, "banned books" cannot be placed within the scope of this standard. In addition, Selected Works of Contemporary Chinese Literature, a collection of works in various genres, cannot be selected. However, the selection criteria of "classical literature" are also evolving with the consciousness evaluation of different times, and are restricted by the aesthetic experiences of different nationalities and national literature. But the selection of "classic literature" is at the expense of the true history of multi-ethnic literature. "Classics" is only the symbol of each era, not the true appearance of literature in that era. Therefore, the literature of a certain nation, a few authors and a few classic works should not be used to generalize and ignore all the literary works of a certain nation, nor should the literary phenomenon of a certain nation be separated from that of other nations. It is not feasible to study Gesar literature without paying any attention to Jangar, and to study Muslim literature with only one research horizon.

The neglect of the inheritance and development of the vivid folk literature of the minorities originates from the historical and cultural view of "elitism". It is a tradition of Chinese culture to promote elitism and attach importance to traditional classics. The Book of Songs, a Confucian classic, experienced the extraction from the Han Dynasty to the Southern Song Dynasty, and finally condensed into the Thirteen Classics of Confucianism, which was regarded as the first of the group. In addition, the position of elites in historical documents reflects the historical and cultural view of "elitism". So, do "heroes make the world" or do people make history? The answer has long been given by the Marxist view of history. Marxism attaches great importance to the value of the people. The driving force of historical development is the people, and it is the working people and heroes who jointly promote the development of history. Whether the objective, impartial and scientific Chinese Marxist view of history can be used to guide the study of Chinese national history is closely related to the rise and fall of the Party and the country. The study of literature with the "elitist" view of literature history marginalizes the study of non-Han literature, which has some flaws: "The derived 'refined literature' and 'classic literature' regard folk literature as 'common literature' or 'non-mainstream literature', which makes the latter suffer the fate of 'unofficial history' and is "classics". "Classical" literature refers to the literary objects that are classified and screened among the writers and works with the aesthetic brand of the times, which are placed in the evaluation system of

excluded from the field of vision of literary historians." [1] American scholar Samir Pearson pointed out in The History of Chinese Thought that "in any modern society where people are not only tools in the hands of elites, it is the only reasonable method to study the thoughts of the elites as well as the masses". [2]

\subsection{The Paradigm Transformation of Chinese Literature Studies under the Path of Multimedia Communication}

Relying on the media of books and periodicals, the traditional literature research is mostly based on the author's text and language as the medium of literary research. Modern Internet multimedia realizes the instant sharing and interaction of huge information through digital terminals, and appears in the public eye as a "new medium" of cultural communication. The speed of information transmission and the amount of information are obvious to all. New media is promoting the transformation and development of Chinese contemporary literature research, and it also provides new research objects and space for literature construction for the transformation of literature research paradigm. For example, WeChat, Kuaishou, Tiktok and Weibo have become a new means and medium of literature communication. These provide a platform and touch space for the performance of oral literature, especially folk literature, such as festival ceremonies. Recently, Nishan Shaman, a functional game jointly hatched by Tencent Game Academy and NEXT Studio, is based on the legendary stories of Shamanism, the primitive religion of ethnic groups in northern China, and takes Shaman as the artistic image. It is developed with the help of multimedia functions. Yi poet Aku Wuwu keeps updating his poems on his micro blog all year round. The fixed 140 characters convey the passionate feelings that quietly win over 10,000 followers every day. Would Akukwu's poems have been read so much if they had been published in a magazine? This is a problem and phenomenon worthy of further investigation, which will not be discussed here. That is to say, new media has changed the expression and inheritance mode of multi-ethnic culture. Current research, however, has been blind to this subtle shift. The spread of new media literature not only builds a media platform for the study of multi-ethnic literature, but also creates a 
new "visibility" in this new cultural space, constructs the new media national literature pattern with network literature as the main body, and provides a new vision for the study of multi-ethnic literature.

\section{EXPANDING THE FIELD OF VISION OF LITERARY RESEARCH}

\subsection{The Consciousness of Literature Researcher to Expand the Category of "Pluralistic Integration" of the National Literature}

Scholars should consciously expand the scope of literature research to the category of "pluralistic integration" of national literature. According to the "historical view of multi-ethnic literature" proposed by two scholars, Liu Daxian and Li Xiaofeng, the content and category of Chinese literature includes all the language-mediated texts, including the written and oral literature of each ethnic group. [1] It is a literary view based on the concept of time and space of the diverse cultural background, language family, national identity and literary tradition of the creative subject. In view of the "elite literature" and "classic literature" deviating from the historical space-time scene and reality, the "language art" with aesthetic quality and emotion which reflects the spirit, character, psychology, customs and traditions of various nationalities should be defined as multiethnic literature. The literary tradition, literary view, literary evaluation standard and the historical status of national literature of each nation should be respected, accepted and recognized. Spiritual products such as "living state" literature, folk tales, proverbs, jokes, ballads and festival ceremonies of various nationalities are an indispensable part of Chinese literature. Prior practice of emphasis on writers' literature over folklore, and on written literature over oral literature, should first be abandoned. In the evolution of human literature, literature is spread by word of mouth, that is to say, oral literature, as the fertile ground for the generation and development of writers' literature, has its unique personality and vigorous vitality. In the age of multimedia information, the rapid development of knowledge and cultural globalization call for attention to the rich and colorful folk cultures of each nation and timely study, otherwise they will be lost in history. For example, some intangible cultural heritages are facing the predicament of having no successors. Therefore, the study of the diversity of national literature has become an inevitable part of literature research.

\subsection{Expansion of Research on Multilingual Writing Among Ethnic Groups}

Wu Yujin, a famous historian, believed that world history has undergone the development of specific historical time and space. In addition to the historical process of material evolution, the evolution of different modes of production and productive forces also led to the change and evolution of social forms. In this process, countries in various regions gradually opened up to the outside world from being isolated and backward to being closely connected and dependent on each other, and influencing each other to become a cohesive whole in human history. [5] Throughout history, in China's multi-ethnic literature, at the beginning, the civilization and man in the Central Plains, the Yi, Rong and Di ethnic groups were isolated, and later they clashed, collided and blended with each other, finally forming a multiethnic literature with rich connotations and diverse forms. In the process of integration and communication between different ethnic groups, in addition to works written in the mother tongue, some inter-lingual and multilingual writings have also emerged, which is another important feature of Chinese literature. For example, the Uygur people of Xinjiang have written literary works in Arabic, Persian, Chinese, Uygur and other languages since ancient times, as well as in multiple languages. Rutifi is such a typical writer. He wrote in many native languages. So far, there has been little research on Rutifi and his works in the academic circle, which has not attracted enough attention. Once a Uyghur teacher gave an academic report in Uighur language. He said that he almost forgot his mother tongue after working in the Chinese atmosphere for a long time. Therefore, when the languages of many nationalities are constantly being eroded to the brink of extinction in the current of "Interlingua" and "Esperanto" culture, it is very rare to write in multiple languages, which allows them to use their own language habits and words to write their national memory, soul and spirit. These works are valuable materials for the study of history and literature of various nationalities and countries.

\subsection{Research on Multidisciplinary Integration from the Perspective of "Multimedia"}

Nowadays, in the era of multimedia, the evolution of the media of literature transmission and inheritance has put forward challenging requirements for the study of contemporary literature. The spread of Gesar, for example, which initially relied on the 
chanting of nomadic singers, now benefits from the popularity of anime cartoons. The expression form of opera, song and dance, and even large-scale TV series make the transmission of Gesar culture continuously expand in time and space, and the form of literature becomes more diversified. The network carrier can perfectly absorb the broad content of Chinese excellent traditional culture, break through the time and regional restrictions, produce cultural collision, and maintain freshness and diversity in the content. [6] It is worth thinking about how to adapt to the trend and pattern of literature globalization. Literary studies should consider its transformation from the perspectives of cultural anthropology, history, philosophy and pedagogy. The multidisciplinary research method, which is caused by the coordinated development and cross penetration of multi-disciplines, is of great benefit to the literature research in the multimedia era.

The origin of Chinese civilization is pluralistic. The consensus in the past was that Chinese civilization originated from the Yellow River Basin and developed gradually and sporadically. The development of historiography has denied the single origin of civilization. Different time, space and regions breed different civilizations, that is, different cultural circles bred by multi-regional civilizations. In the process of constant blending, collision, communication and reconstruction of farming culture and nomadic culture, today's rich and brilliant cultural patterns have been formed. Such diversity is the main characteristic of Chinese literature. Such diversity can neither talk about literature without talking about the regional factors it nurtures, nor escape the influence of ethnic languages, traditional customs, historical memory and other factors. Therefore, as the most important carrier form of culture, the research paradigm of literature needs to be transformed. Natural regional factors, geographical relations and diverse national cultures should be studied from the vertical perspective of historical time sequence and the horizontal integration of pluralism. There is no doubt that online multimedia literature has expanded the scope of literature research.

\section{THE SIGNIFICANCE OF EXPANDING THE HORIZON OF LITERARY RESEARCH}

\subsection{To Reproduce the Original Appearance of Chinese Literature}

In order to give a more comprehensive and detailed interpretation of the whole picture of Chinese literature, it is necessary to change the research paradigm and expand the research horizon. The multi-regional, multi-ethnic, multi-modal, multilingual and multi-traditional characteristics of Chinese literature define the object of Chinese literature study and more clearly outline the boundary line of Chinese literature. Throughout the ages, various ethnic groups have formed a unified and diversified cultural pattern, which includes different creative forms, whether textual or oral. The "Yimakan storytelling" of the Hezhen nationality, the epic "Le"e Te Yi" of the Yi nationality, the "Folk Song by Liu San Jie" of the Zhuang nationality, and the "Meng Jiangnv bringing down the Great Wall with tears" of the Han nationality, all of these literary achievements form interweave together to form a magnificent and extraordinary symphony. They provide a window into the psychological processes and spiritual beliefs of different ethnic groups from ancient times to the present day.

However, it is still difficult to study the Han literature and the literature of other nationalities, the literature of writers and the folklore of various nationalities as an organic whole. The overwhelming mass culture of today seems to bridge the gap between classic and elite culture, but this is only a superficial phenomenon. The expansion of the field of literature research requires the re-examination and study of the "popular literature", that is, the folk literature and network literature of various nationalities, which are covered by the "classic", "elite" and "elegant culture" Chinese literature in the past, which is helpful to restore the historical panoramas of Chinese multi-ethnic literature. Only in this way can we form a literary map of China that is consistent with Chinese history.

\subsection{To Enrich the Traditional Chinese Culture System}

Literature is not only an important part of culture, but also the main carrier of culture. The reason why Chinese culture is brilliant, rich and lasting is that it is the aggregation of the excellent cultural achievements of various ethnic groups. For a long 
time, the one-sided and narrow view of literature history, which equates the Chinese literature with the Chinese literature, the elite literature with the mass culture, and the national literature with the literature of the minority nationalities, has combined the Confucian, Buddhist and Taoist cultures and labelled them as the excellent traditional Chinese culture. Such practice should be discarded. The excellent traditional Chinese culture is composed of the excellent traditional cultures of various nations. The fine traditional cultures of various ethnic groups and the fine Chinese culture learn from each other and appreciate each other. They are interwoven, integrated and complementary to each other. Therefore, different ethnic groups have different histories and cultural traditions. However, their excellent culture is integrated with each other in spiritual pursuit, ideological connotation and value orientation. Therefore, the longitude and latitude of the traditional culture of various ethnic groups have greatly enriched the excellent traditional culture of China. Liu Yuejin once called for strengthening the study of Chinese culture and introducing the excellent cultures of different ethnic groups into the classroom, which is not only the inheritance, popularization and protection of the classical knowledge of different ethnic cultures, but also an important work of collective identification of ethnic cultures. [1]

\subsection{To Promote the Development of National Literature Theory and the Construction of Critical Discourse System}

Western literary theory is not universal, and not all scientific literary theories can solve the specific problems of Chinese multi-ethnic literature. Chinese literature is a diverse and unique discipline of literature, reflecting the richest and most diverse life and human feelings in the world. In China, there are extensive and profound works of classical literature, such as Wen Xin Diao Long by Liu Xie, Wen Fu and Shi Pin, whose literary creation, style and critical discourse system are important national literary theories. The theory of Chinese traditional poetry and prose is often taken as the research object, but the rich and vivid phenomenon of multi-ethnic literature theory and the complex but unique literary thought and the construction of theory are rarely studied. For example, the Yi Poetry and Literature Theory written and translated by the $\mathrm{Yi}$ theorists Ju Shizhe and Ameninnu, the $Y i$ Poetry Theory written and translated by Amaini, and the Dai Poetry Theory written and translated by Hubameng of the Dai and published by Yan Wenbian, have attracted the attention of the academic circle and been praised as an important discovery. [3] In addition, there are Loubulun's On Poetic Writing, Amaini's On Poetic Law of Yi Language, and Butaetchou's On Poetic Writing. Selected Literary Theories of Ethnic Minorities in Chinese Dynasties, the first comprehensive collection of literature and art works of ethnic minorities edited by Wang Yiding and Maimaiti Zunong from Xinjiang, includes 66 works by 36 commentators from 15 ethnic minorities, initially showing the literary and art theories of ethnic minorities. [4] However, these have not aroused the attention of the researchers of ancient Chinese literature, which shows that the Chinese literary theory has not completely constructed an organic whole which takes the Han literary theory as the resource core and absorbs the traditional literary theories of ethnic minorities. The evaluation discourse system and theoretical system of the research object and research paradigm have not been improved.

Literature is a dance performance for some nationalities, a religious belief for others, a festival performance ceremony for others, and a combination of music and dance for others. Therefore, in addition to textual literature, the living literature of these nationalities needs to be included in literary theory, which requires the rating standards of traditional literary classics of various nationalities to be included in the evaluation system of Chinese national literature, and then to construct a truly diversified and integrated literary evaluation system.

\section{CONCLUSION}

Literature is the reflection of the life, the material of literature stems from the life, the different soil and water that gives birth to culture brings about different fruit and fruit. It is useless to deduce and study "foreign culture" with the inherent thinking mode and evaluation system. In order to realize equal communication and dialogue with the world culture, the most important thing is to adhere to the difference of the ethnic culture, creatively abide by the spiritual quality of the independence of the ethnic culture, and safeguard the dignity of the native culture of the ethnic group. In addition, some scholars have proposed that the study of Chinese literature should be in line with international standards, and that Chinese literature, a part of world literature, should be established as an independent discipline and incorporated into the system of Chinese literature. It is of great significance to broaden the horizon of 
literary research. The diversity of human literature determines that each nation has its own literary system. Each national literature has a wide range of acceptance groups, and there is a larger space between the creator and the recipient of aesthetic standards and evaluation standards. Therefore, it is unscientific to judge Dong Opera or Tibetan Opera by classical standards such as the performance standards, structural characteristics and tone of Peking Opera, which is called the "quintessence of China". "Beauty represents itself with diversity and integrity" is the best way to highlight the evaluation of diversified literary classics. It respects the literary theories and evaluation standards of each nation, enriches and improves the classical treasure house of Chinese literature, and enhances the vitality of Chinese literature. Therefore, breaking through the traditional Chinese research paradigm and expanding the field of literature research not only breaks through the research base of "Chinese literature" and "elite literature", but also breaks through the framework of literary poetry, novels, prose and other literary genres, and expands the space and time category of traditional literature research. This is of great significance, and it is also a long way for literary researchers to go.

\section{AUTHORS' CONTRIBUTIONS}

This paper is independently completed by Xuelian Sheng.

\section{REFERENCES}

[1] Li Xiaofeng, Liu Daxian. Multinational literary Historical View [M]. Beijing: China Social Sciences Press, 2006.

[2] Collated by Zhao Yifeng. Dialogue between Eastern and Western historical viewpoints Discussion on historical viewpoints with American scholar Samir Pearson [J]. Journal of Northeast Normal University, 2005, Issue 5.

[3] Wang Song. "An Important Discovery Introduction (On Dai Poetry)", in the first volume of "On Dai Poetry".

[4] Yu Naichang. An overview of Chinese minority literary theory $[\mathrm{J}]$. Journal of Yunnan Minzu University, 1995, No. 5.

[5] Ouyang Kexing. Thoughts on the construction of contemporary Chinese multi-ethnic literature history [J]. National Literature Research, 2008, No. 2. (in Chinese)
[6] Chen Bo, Qiu Minglei. Chinese excellent traditional culture and network communication - Inheritance and development in the Internet Age [J]. Trends in Social Sciences, 2021, No.1. (44) 